\title{
Special issue on satellite communication systems and networking
}

\author{
Athanasios D Panagopoulos ${ }^{1 *}$, Sandro Scalise ${ }^{2}$, Bjorn Ottersten ${ }^{3}$, John D Kanellopoulos ${ }^{4}$ and Paolo Burzigotti ${ }^{5}$
}

Satellite Communications (SatCom) will have a crucial role in Next Generation Networks and in shaping the Future Internet. This is mainly due to the inherent features of SatCom Networks such as global coverage, cost effectiveness for broadcasting and multicasting connectivity, capability for providing broadband interactive services in remote areas, and emergency services. SatCom networks provide the foundations of European and worldwide digital information networks, and are already playing important roles in the current Internet such as: (a) providing broadband services to citizens in rural areas, to passengers on board of vessels, trains, or aircrafts; (b) delivering content to network head; (c) distributing data to the banking, business, health, governmental sectors; (d) providing connectivity in the Internet backbone; (e) backhauling of other access technology; and (f) providing quick Internet access in emergency scenarios.

In general, the SatCom operators and agencies are trying to follow the progress in technology of the terrestrial communication networks and benefit from their significant research achievements. On the other hand, the satellite systems, compared to terrestrial systems, have some particular characteristics such as service coverage, link geometry, propagation delay, channel impairments, interference scenarios, and physical layer interface. Additionally, we can distinguish between different SatCom systems variants depending on: the orbit, the users' mobility, the operating frequency bands, group size of intended users, multiplexing scheme, type of application, and availability of FMTs. The well-accepted satellite standards that have been developed by ETSI are DVB-S2 and $\mathrm{DVB} / \mathrm{SH}$ for fixed/mobile satellite broadcasting applications. Moreover, Broadband SatCom systems, with their global access and broadcasting capabilities, are well suited to answer to the requirements of the

\footnotetext{
* Correspondence: thpanag@ece.ntua.gr

'School of Electrical and Computer Engineering, Mobile Radio Communications Laboratory, National Technical University of Athens, Iroon Polytechniou 9, Zografou, Athens 15780, Greece

Full list of author information is available at the end of the article
}

information society. In this context, the $\mathrm{Q} / \mathrm{V}$ band frequencies will play a key role in enabling challenging and unproven broadband communications missions for a wide range of applications and leading to the implementation of Terabit Satellite Networks. The Q/V frequency band may be employed for feeder links, for direct-to(fixed, mobile) user satellite applications and as part of the whole integrated network. Some of these issues are of great interest by European Space Agency as this is testified with the launch of Alphasat in 2012. The focus of this Special Issue is to present high-quality unpublished research papers on recent advances in the wider area of SatCom Systems and Networks by experts from industry, academia, and space agencies. Our call for papers attracted numerous submissions worldwide. After a rigorous review process, we present the following six papers.

The first paper entitled "State Modelling of the Land Mobile Propagation Channel for Dual-Satellite Systems" [1] targets on the evaluation and modeling of the multi satellite propagation channel for land mobile users for a high variability of angle diversity constellations presenting results from ESA Project MILADY. Measurements and re-simulated data are analyzed for various elevation angle combinations and azimuth separations in terms of the state probabilities, state duration statistics, and the correlation coefficient.

The second paper entitled "On the Capacity of a SIMO Land Mobile Satellite System at C-Band: Polarized and Depolarized Received Field" [2] evaluates theoretically the capacity of an LMS (SIMO) system utilizing uniform linear arrays at the receiver terminal operating at $\mathrm{C}$ Band. Additionally, polarization effects are introduced and capacity results are given taking into account the depolarization.

In the next paper entitled "Enhancement of wireless positioning in outdoor suburban non-line-of-sight (NLOS) environment using hybrid-network-GPS" [3], a method for locating mobile terminal in outdoor suburban NLOS environment, using hybrid-network-GPS 
system, is introduced. The proposed method uses constraint nonlinear optimization to minimize the NLOS error.

In the fourth paper entitled "Linear and nonlinear techniques for multibeam joint processing in satellite communications" [4], joint multiuser processing techniques for multibeam satellite systems, towards Terabit Satellite Concept, are investigated. More specifically, the performance of linear precoding is examined in the forward link, with optimal nonlinear precoding (i.e., dirty paper coding) acting as the upper performance limit. Similarly, in the return link the concept of linear filtering (i.e., linear minimum mean square error) is studied with the optimal successive interference cancellation acting as the performance limit.

The next paper entitled "Residue code-based low cost SEU-tolerant FIR filter design for OBP satellite communication systems" [5] proposes a dual modules (DM) plus checking module based on residue code (DM-CRC) architecture for SEU-tolerant FIR design. Moreover, a multi-sample checking DM-CRC (MSC-DM-CRC) is further proposed in order to reduce the fault missing rate.

In the last paper entitled "Performance study of multiuser interference mitigation schemes for hybrid broadband multi beam satellite architectures" [6], precoding and multi-user detection schemes for multi beam satellites comparing are examined. Moreover, hybrid onboard on-ground beamforming techniques are compared with fully ground-based beamforming.

\section{Competing interests}

The authors declare that they have no competing interests.

\begin{abstract}
Acknowledgments
The guest editors of this Special Issue wish to thank all the contributing authors for submitting high-quality papers to this special issue. We would also like to thank all reviewers for their thorough and valuable evaluation of the papers within the short stipulated time. Their careful reviews and valuable comments helped us select the papers as well as improve the quality of this special issue. We would like to further thank Prof. Luc Vandendorpe, Editor-in-Chief, EURASIP Journal on Wireless Communications and Networking, as well as the whole Editorial Board for their support. Finally, we owe a debt of gratitude to the whole editorial and publications staff of EURASIP Journal on Wireless Communications and Networking that provided us assistance and continuous support throughout the whole process. Part of this work has been carried out under the framework of THALES-NTUA MIMOSA funded by by EU and GSRT. Finally, we hope that the readers will enjoy the contributions on Satellite Communication Systems and Networking in this Special Issue.
\end{abstract}

\footnotetext{
Author details

${ }^{1}$ School of Electrical and Computer Engineering, Mobile Radio Communications Laboratory, National Technical University of Athens, Iroon Polytechniou 9, Zografou, Athens 15780, Greece. ${ }^{2}$ Institute of Communications and Navigation, DLR (German Aerospace Center), Oberpfaffenhofen, Germany. ${ }^{3}$ Security and Trust, University of Luxembourg, Luxembourg L-1359, Germany. ${ }^{4}$ Wireless and Satellite Communications Group, School of Electrical Computer Engineering, National Technical University of Athens, 9 Iroon Polytechniou Street, Zografou 15780, Greece. ${ }^{5}$ ESTEC, European Space Agency, Noordwijk, The Netherlands.
}

Received: 19 August 2012 Accepted: 19 August 2012 Published: 7 September 2012

\section{References}

1. D. Arndt, A. Ihlow, T. Heyn, A. Heuberger, R. Prieto-Cerdeira, E. Eberlein, "State Modelling of the Land Mobile Propagation Channel for Dual-Satellite Systems". EURASIP J Wirel Commun Netw (2012)

2. N. Moraitis, P. Horvath, P. Constantinou, I. Frigyes, "On the Capacity of a SIMO Land Mobile Satellite System at C-Band: Polarized and Depolarized Received Field". EURASIP J Wirel Commun Netw (2012)

3. S.O. Al-Jazzar, Enhancement of wireless positioning in outdoor suburban NLOS environment using hybrid-network-GPS systems. EURASIP J Wirel Commun Netw (2012)

4. D. Christopoulos, S. Chatzinotas, G. Zheng, J. Grotz, B. Ottersten, "Linear and nonlinear techniques for multibeam joint processing in satellite communications". EURASIP J Wirel Commun Netw (2012)

5. W. Yang, Z. Gao, X. Chen, M. Zhao, J. Wang, Residue Code Based Low Cost SEU-Tolerant FIR Filter Design for OBP Satellite Communication Systems. EURASIP J Wirel Commun Netw (2012)

6. J. Arnau, B. Devillers, C. Mosquera, A. Perez-Neira, Performance study of multiuser interference mitigation schemes for hybrid broadband multibeam satellite architectures. EURASIP J Wirel Commun Netw (2012)

doi:10.1186/1687-1499-2012-283

Cite this article as: Panagopoulos et al: Special issue on satellite communication systems and networking. EURASIP Journal on Wireless Communications and Networking 2012 2012:283.

\section{Submit your manuscript to a SpringerOpen ${ }^{\circ}$ journal and benefit from:}

- Convenient online submission

- Rigorous peer review

- Immediate publication on acceptance

- Open access: articles freely available online

- High visibility within the field

- Retaining the copyright to your article

Submit your next manuscript at $\gg$ springeropen.com 